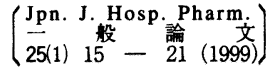

\title{
経腸成分栄養療法実施時の薬物吸収性変化
}

\author{
井関 健, 川端志津, 金内美妃, 宮崎勝巳* \\ 北海道大学医学部附属病院薬㓲部 $\dagger$
}

\section{Changes in the Absorption Behaviour of Drugs when Combined with Oral Nutrition Support}

\author{
KEN ISEKI, SHIZU KAWABATA, MIKI KANEUCHI and KATSUMI MIYAZAKI* \\ Department of Pharmacy, Hokkaido University Hospital†
}

\author{
$\left(\begin{array}{l}\text { Received June 8, } 1998 \\ \text { Accepted October 13, } 1998\end{array}\right)$
}

The oral bioavailability of such ionized drugs as ceftibuten, salicylic acid, and famotidine, when coadministered with enteral nutrition support was assessed in rats. Orally active nutrition support (HepanED ${ }^{\circledR}$, Twinline ${ }^{\circledR}$, Enterued ${ }^{\circledR}$ ) has exhibited an inhibitory effect on the absorption of ceftibuten from the rat intestine, thus suggesting this drug to not demonstrate the desired therapeutic effect. In Loop experiments using the rat intestine, the absorption rates of ceftibuten, salicylic acid and cimetidine were found to decreas to similar extents when combined with enteral feeding products. The suppression by such enteral feeding products is considered to be due to the interaction between the drug and the component(s) of the oral nutrition support, but is not thought to be related to the gastric emptying time. On the other hand, the absorption of levofloxacin, a zwitterionic compound, from the intestinal loop was not affected at all by HepanED ${ }^{\circledR}$. This result correlates with the previous data ${ }^{4)}$ which showed no inhibitory effect of Enterued ${ }^{\circledR}$ on cephalexin absorption. These findings therefore suggest a common relationship between the structures of the drug molecules and the inhibition behavior observed during enteral nutrition support.

Key words - oral bioavailability of ionized drugs, orally active nutrition support, enteral feeding products, inhibition behavior, intestinal absorption, drug interaction, rat

緒 言

経腸栄養剈は，術後患者や経口的な食事攝取が 困難な患者の栄養保持に用いられ，原疾患治療薬 と併用されることが多い. 消化吸収されやすい形 に加工されたこれらの製片は一般の食事以上に薬 物吸収に影響を与え得ると考えられるが，その詳

$\dagger$ 札幌市北区北14条西5丁目; Kita-14-jo, Nishi-5chome, Kita-ku, Sapporo, 060-8648 Japan
細については検討された例は少ない。近年，この 経腸栄養荗の服用により低分子の水溶性物質や薬 物の消化管吸収性が変化することが明らかになっ ている1,3).また，著者らはペプチドを主体とし た半消化態栄養脷エンテルード（テルモ(株）等が 経口セフェム系抗生物質の消化管吸収を抑制し血 中濃度の低下を引き起こすことを報告しだ).

このセフェム系抗生物質の吸収抑制効果は，ア

ミノ酸を主たる窒素源とする成分栄養剈へパン 
$\mathrm{ED}$ (ヘキスト・マリオン・ルセル(株) によって も認められたことから，この吸収抑制のメカニズ ムはぺプチド輸送機構(5)に起因するものではない ことが示唆されている. 今回, 著者らは薬物吸収 に及ぼすこれら経腸栄養剤の消化管吸収抑制機構 ならびに吸収変動を生じさせる経腸栄養剤の共通 特性を明らかにする目的で経腸栄養剈共存時にお ける薬物の吸収動態を種々検討した。

\section{実験材料および方法}

\section{1. 使用薬物・試薬}

セフチブチン（CETB）およびセファレキシン (CEX) 原末は塩野義製薬(株より，シメチジン (CMD)は藤沢薬品工業(株より, またレボフロキ サシン（LVFX）は第一製薬(株より各々分与され たものを使用した。エンテルード((株)テルモ)，へ パン ED (ヘキスト・マリオン・ルセル(制)), ツイ ンライン (大塚製薬(株)）は各々市販品を購入して 用いた. その他の薬物原末. 試薬類はすべて和光 純薬(株)より特級試薬を購入した。

\section{2. 動物実験}

1 ）ラット小腸ループからの薬物吸収

Wistar 系雄性ラット（体重180～250gr）を15時 間絶食後, ペントバルビタール麻酔下にて開腹し 胆管を結禁した後幽門下 $3 \mathrm{~cm}$ の部位から約 $20 \mathrm{~cm}$ の小腸ループを作成した.ループ内を $37^{\circ} \mathrm{C} に$ 保温 した生理食塩液で洗浄後, modified Ringer 溶液 $(\mathrm{pH} 6.8)^{6)}$ 溶液または経腸栄養㓮にて調製した薬 物溶液 $2 \mathrm{~mL} \mathrm{(CETB} \mathrm{として} 2.5 \mathrm{mg}$, サリチル酸と して $1.25 \mathrm{mg}, \mathrm{CMD}$ として $3 \mathrm{mg}, \mathrm{LVFX}$ として 0.5 $\mathrm{mg}$ の各々)を注入した. 注入後 $10,20,30,45$, $60,90,120$ 分後に頝静脈より $0.25 \mathrm{~mL}$ ずつ採血 し薬物の定量に供した.

各経腸栄養剤による小腸管腔内の前処理はラッ トに小腸ループを作成した後, 経腸栄養剤 $2 \mathrm{~mL}$ を注入した．10分間放置後，注射筒を用いて栄養

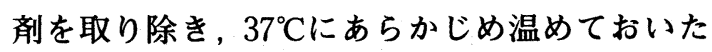
Modified Ringer 溶液 $10 \mathrm{~mL}$ で洗浄した後, 薬液 2 $\mathrm{mL}$ (CETB として2.5mg)をループ内に注入した.
薬液注入後経時的に採血し定量に供した。

2 ）ラット経口投与後の血漿中薬物濃度推移 ラットを15〜18時間絶食後, エーテル麻酔下で CETB 溶液（ $7 \mathrm{mg} / \mathrm{mL} ）$ を胃ゾンデを用いて経口 投与した（投与量 $10 \mathrm{mg} / \mathrm{kg}$ weight）. 投与後 15 , 30,45 分， 1，2，3，4，6時間後にエーテル 麻酔下心臓より採血し $(0.25 \mathrm{~mL})$ 遠心分離後, 得られた血漿を定量に供した。

\section{3. 薬物の定量}

各薬物のラット血槳中薬物濃度は, すべて HPLC 装置（日立製作所, L-6000）を用いて測定 した. CETB を含む血槳 $0.1 \mathrm{~mL}$ を蒸留水で 2 倍に 希釈後, クロロホルム/メタノール混液 $(2: 1)$ $1.0 \mathrm{~mL}$ を加え激しく擋拌後（30秒）遠心分離し $(7,000 \mathrm{~g} ， 20$ 分) 水層を HPLCに注入した. LVFX の場合は同様に血漿 $0.1 \mathrm{~mL}$ をリン酸緩衝液 $(\mathrm{pH}$ 5.5）で 2 倍に希釈後クロロホルム $1.0 \mathrm{~mL}$ を加え 激しく擤拌後 (30秒) 遠心分離し $(7,000 \mathrm{~g}, 10$ 分) 水層を HPLCに注入した.サリチル酸の血漿中 濃度の測定では血槳にメタノール 2 倍容を加えて 激しく擋拌後 (30秒) 遠心し $(5,000 \mathrm{~g}, 20$ 分) 上 清をHPLCの注入試料とした. CMDの定量は Ziemniak $ら^{7)}$ おび Abdel-Rehim ら ${ }^{8)}$ 方法を組み 合わせ以下のような条件を設定した。すすおち血 漿 $0.1 \mathrm{~mL}$ にメタール溶液 $0.15 \mathrm{~mL}, 25 \mathrm{mM}-\mathrm{NaOH}$ 溶液 $25 \mu \mathrm{L}$, アセトニトリル $2 \mathrm{~mL}$ を添加し浸盪 後（5 分）遠心し $(1,000 \mathrm{~g}, 10$ 分）不溶性成分を 除去した. 上清 $(1.9 \mathrm{~mL})$ に $20 \mathrm{mM}-\mathrm{HCl}$ を含む飽 和食塩水 $1 \mathrm{~mL}$ を加え, 振湯後遠心することで水 層と有機層に分離した。水層を $1 \mathrm{~mL}$ 取り $0.1 \mathrm{~mL}$ の $5 \mathrm{mM}-\mathrm{NaOH} て ゙ 中$ 和してから $2 \mathrm{~mL}$ のアセトニ トリルにて抽出し, その有機層を蒸発乾固させて HPLCの注入資料とした. HPLC 測定条件は次の とおりである。 CETB 測定：カラム；日立\#3053 $(5 \mu \mathrm{m}, 4.0 \mathrm{~mm}$ (i.d.) $\times 250 \mathrm{~mm}$ ，日立製作所），波 長; $262 \mathrm{~nm}$, 流速; $0.8 \mathrm{~mL} / \mathrm{min}$, 温度; $55^{\circ} \mathrm{C}$, 移 動層; $50 \mathrm{mM}$ クエン酸/100mM-KC1：アセトニト リル $(9: 1, \mathrm{pH} 3.0)$. LVFX 測定: カラム : イ ナートシル ODS- $3(5 \mu \mathrm{m}, 4.0 \mathrm{~mm}$ (i.d.) $\times 250$ 
$\mathrm{mm}$ ，ガスクロ工業), 波長: $265 \mathrm{~nm}$, 流速：0.9 $\mathrm{mL} / \mathrm{min}$, 温度: $50^{\circ} \mathrm{C}$, 移動層; $0.05 \mathrm{M}-\mathrm{KH}_{2} \mathrm{PO}_{4}$ ( $2 \%$ 醀酸含む)：メタノール $(3: 1)$.

サリチル酸測定：カラム; ERC-ODS-1161（3 $\mu \mathrm{m}, 6.0 \mathrm{~mm}$ (i.d.) $\times 100 \mathrm{~mm}$, (株)イー・アール・シ 一), 波長; $230 \mathrm{~nm}$, 流速: $0.8 \mathrm{~mL} / \mathrm{min}$, 温度 ; 55 ${ }^{\circ} \mathrm{C}$, 移動層; 酢酸 : メタノール: 水 $(3: 43: 54)$

CMD 測定: カラム: 日立\#3053, 波長: 228 $\mathrm{nm}$, 流速: $0.7 \mathrm{~mL} / \mathrm{min}$, 温度: 室温, 移動層;

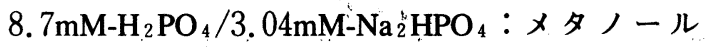
$(23: 17)$.

\section{結果}

\section{1. 経口投与後の血中湌度推移}

薬物経口投与時の血中動態におよぼす経腸栄養 剤ヘパン ED併用の影響を検討した。 CETBの投 与量は $10 \mathrm{mg} / \mathrm{kg}$ (体重) とした。 ※パン EDを同 時に投与した時, Fig. $1 \mathrm{~A}$ に示すように楽物単独 投与時と比べて CETB の血中濃度は低下し, 吸 収が抑制される傾向を認めた。 CETB 投与の30分 前へパン ED を投与した場合, 生理食塩水を前投
与したコントロールに比較しても吸収は著しく抑 制され，その抑制の程度は同時投与したときに比 べて著しく大きいことが示された（Fig. 1 B).

\section{2. in-situ loop 実験}

経腸栄養剤による吸収抑制作用の詳細を明らか にする目的で, ラット小腸ループを用いて経腸栄 養剤の影響を解析した。

1）各種経腸栄養㓣の CETB 吸収におよぼす 影響

3 種類の経腸栄養凨と CETBを併用したとき の血中濃度推移を Fig. 2 に示す. 経口投与の場 合と同様にへパン ED 併用時には, CETB の吸収 は著しく低下することが示された（Fig. 2 A）. この吸収抑制効果は，ツインラインやエンテルー ドを併用した場合でも認められ，CETBの血漿中 濃度は薬物単独投与時に比べ有意な低下を示した (Fig. 2 B,C). これらの結果は各種経腸栄養剈の 同時投与により CETB の吸収は抑制され十分な 血中濃度が得られないことが示唆している.

2 ）他の薬物吸収に及ぼす経腸栄養剤の影響 構造的に共通性のない各種薬物の吸収に及ぼす
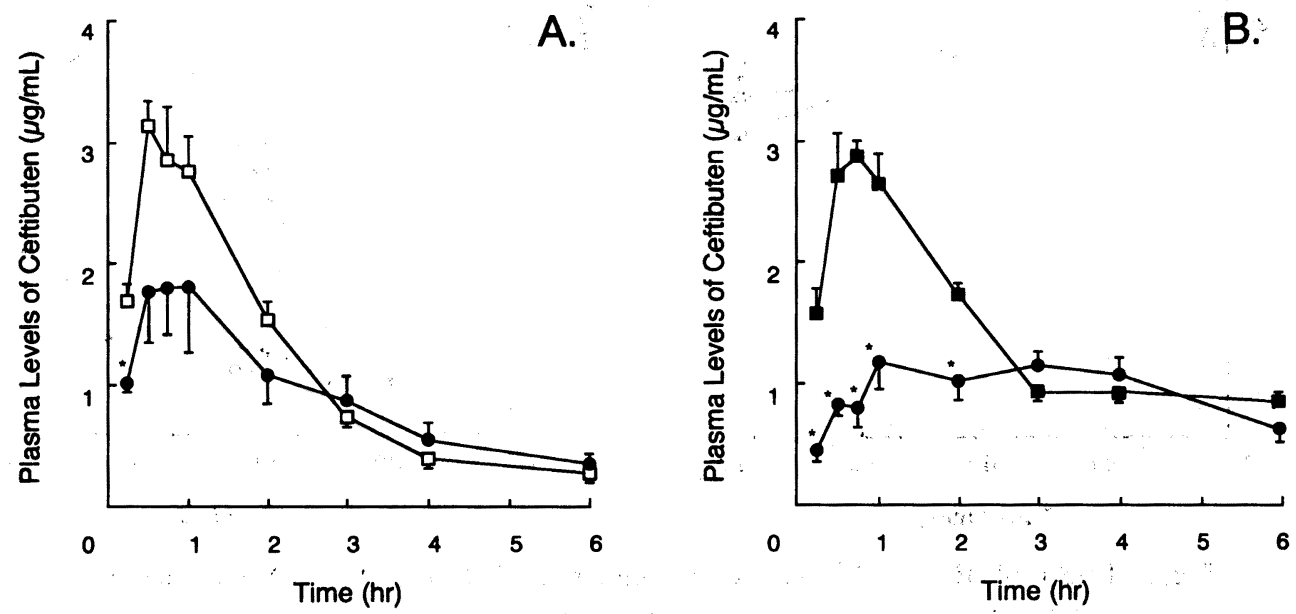

Fig. 1. Plasma Level Behavior of Ceftibuten after Oral Administration $(10 \mathrm{mg} / \mathrm{kg}$ body weight) to Rat in the Combination with $(\bigcirc)$ or without $(\square, \square)$ HepanED $^{\circledR}$

A) Simultaneous coadministration of ceftibuten and HepanED ${ }^{\circledR}$.. B) HepanED ${ }^{\circledR}$ (O) or saline (ם) was administered $30 \mathrm{~min}$. before ceftibuten dosing. Each point represents the mean with S.E.M. of four determinations. ${ }^{*} ; p<0.05$, Significantly different from control ( $\square$; without HepanED ${ }^{\circledR}$ ). 

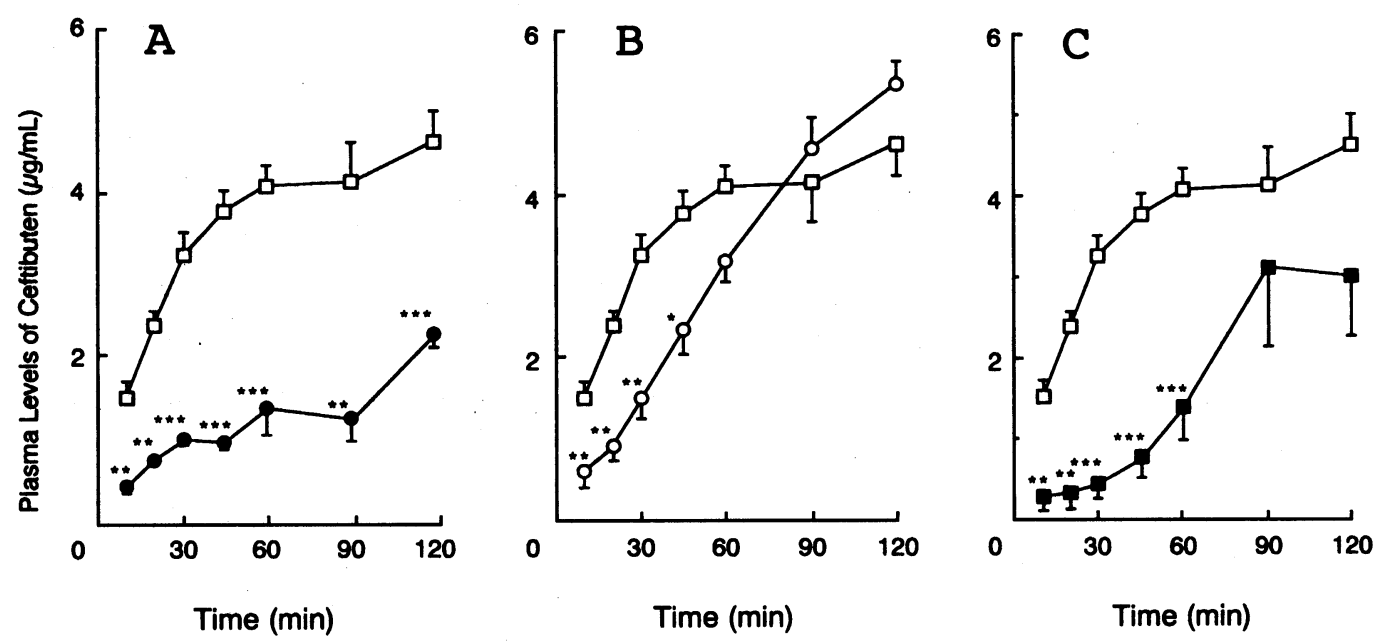

Fig. 2. Effect of Oral Nutrition Supports on Ceftibuten Absorption from Rat Intestinal Loop

A) with (O) or without $(\square)$ HepanED ${ }^{\circledR}$; B) with $(\bigcirc)$ or without $(\square)$ Twinline ${ }^{\circledR}$; C) with $(\square)$ or without $(\square)$ Enterued ${ }^{\circledR} .2 .5 \mathrm{mg}$ Ceftibuten/ $2 \mathrm{~mL}$ was administered. Each point represents the mean with S.E.M. $(\mathrm{n}=6-7){ }^{*} ; p<$ $0.05,{ }^{* *} ; p<0.01,{ }^{* * *} ; p<0.001$, Significantly different from control (without Oral Nutrition Supports).
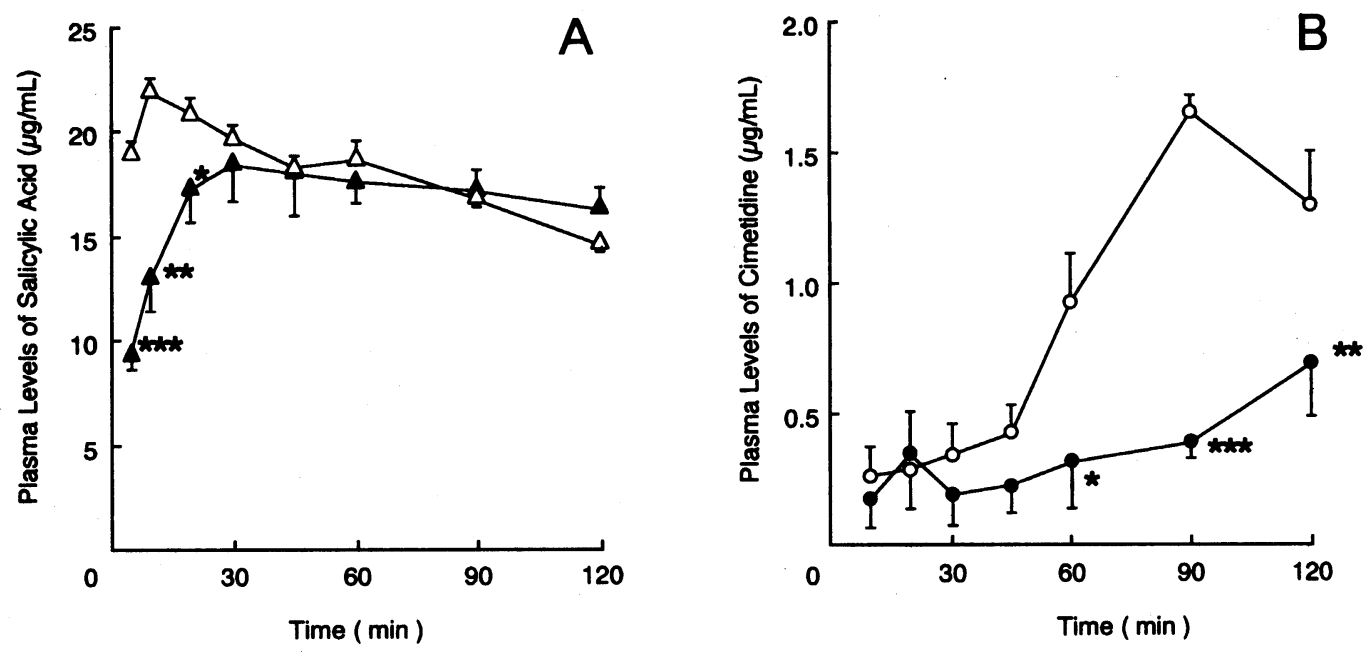

Fig. 3. Effect of HepanED ${ }^{\circledR}$ on the Absorption of Salicylic Acid (Anion) and Cimetidine (Cation) from Rat Intestinal Loop

A) Salicylic Acid $(1.25 \mathrm{mg} / 2 \mathrm{~mL})$ with $(\Delta)$ or without $(\Delta)$ HepanED $^{\circledR}$; B) Cimetidine $(3.0 \mathrm{mg} / 2 \mathrm{~mL})$ with $(O)$ or without $(O)$ Twinline ${ }^{\circledR}$. Each point represents the mean with S.E.M. $(\mathrm{n}=4-5) .{ }^{*} ; p<0.05,{ }^{* *} ; p<0.01,{ }^{* * *} ; p<$ 0.001 , Significantly different from control (without HepanED ${ }^{\circledR}$ ). 
ヘパン EDの効果について検討した.

Fig. 3 に示したように，カチオン型薬物である シメチジン, アニオン型構造を有するサリチル酸 のいずれの薬物も, 吸収の初期において血中濃度 の低下が見られた。しかしながら，両性イオン型 構造をとるレボフロキサジンの小腸ループからの 吸収はへパン ED 共存によっては変化せず，血中 推移は単独投与の場合とほとんど同じであること が示された（Fig. 4 ）。

3 ) 経腸栄養荗の濃度依存的吸収抑制効果

抑制効果の大きかったエンテルードとヘパン EDについてそれぞれの共存濃度の影響について 検討した.

Fig. 5 に示したように, ヘパン ED の濃度を通 常調製濃度の $1 / 2,1 / 4$ に生理食塩水を用いて 希釈した溶液と、CETB を併用した時, CETB の吸 収はしだいに回復し, 経腸栄養剤の吸収抑制効果 には荟度依存性が認められた。 また, 吸収速度 （10-30分の血漿中濃度值を時間に対してプロット
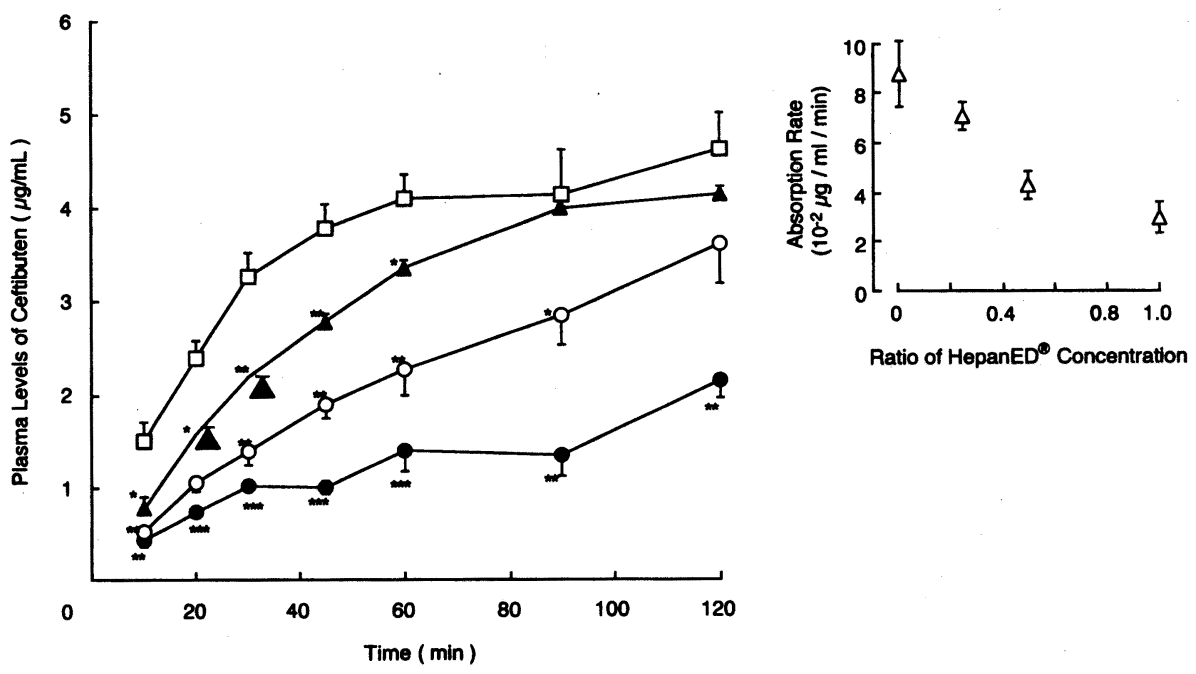

Fig. 5. Dose Dependency of HepanED ${ }^{\circledR}$ on the Absorption of Ceftibuten from Rat Intestinal Loops and Relationship between the Concentration of HepanED ${ }^{\circledR}$ and the Absorption Rate of Ceftibuten (inset)

Ceftibuten $(2.5 \mathrm{mg} / 2 \mathrm{~mL})$ were administered with $(\mathbf{O}$; original concentration, $\bigcirc$; diluted twice concentration, $\boldsymbol{\Delta}$; diluted 4-times) or without $(\square)$ various concentration of HepanED ${ }^{\circledR}$. Each poit represents the mean with S.E.M. $(n=4$ -6). ${ }^{*} ; p<0.05,{ }^{* *} ; p<0.01,{ }^{* * *} ; p<0.001$, Significantly different from control (without HepanED ${ }^{\circledR}$ ). 


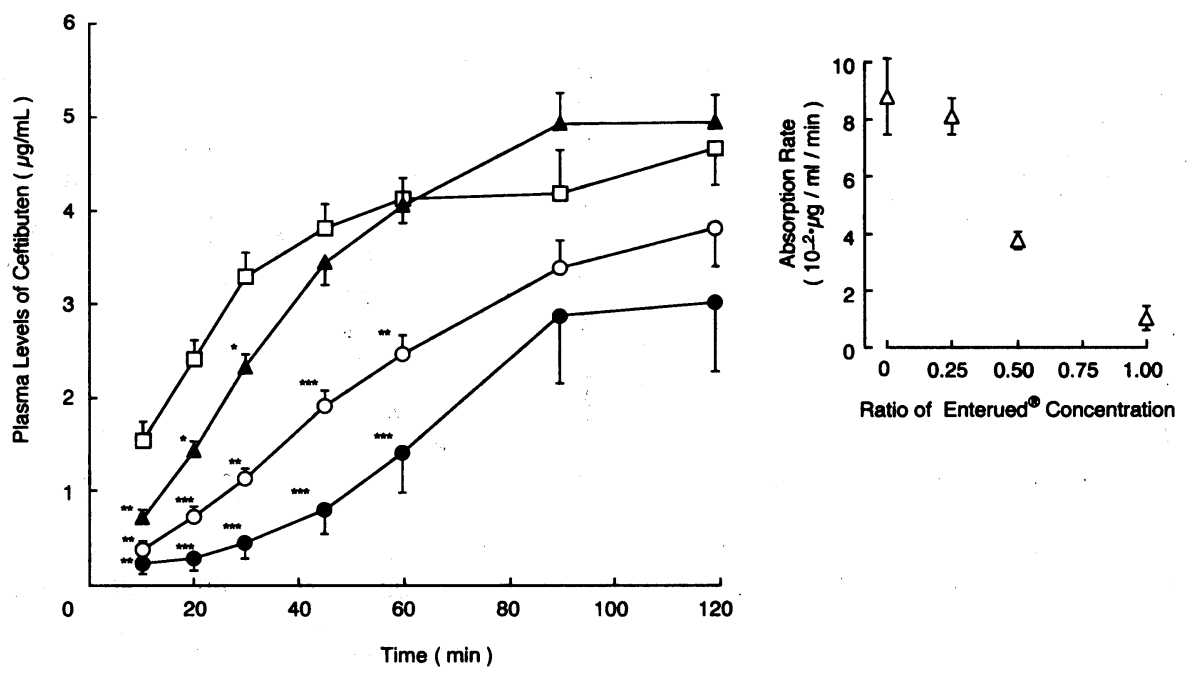

Fig. 6. Dose Dependency of Enterued ${ }^{\circledR}$ on the Absorption of Ceftibuten from Rat Intestinal Loops and Relationship between the Concentration of Enterued ${ }^{\circledR}$ and the Absorption Rate of Ceftibuten (inset)

Ceftibuten $(2.5 \mathrm{mg} / 2 \mathrm{~mL})$ were administered with $(0$; original concentration, $\bigcirc$; diluted twice concentration, $\boldsymbol{\Delta}$; diluted 4-times) or without $(\square)$ various concentration of Enterued ${ }^{\circledR}$. Each poit represents the mean with S.E.M. $(n=4)$. ${ }^{*} ; p<0.05,{ }^{* *} ; p<0.01,{ }^{* * *} ; p<0.001$, Significantly different from control (without Enterued ${ }^{\circledR}$ ).

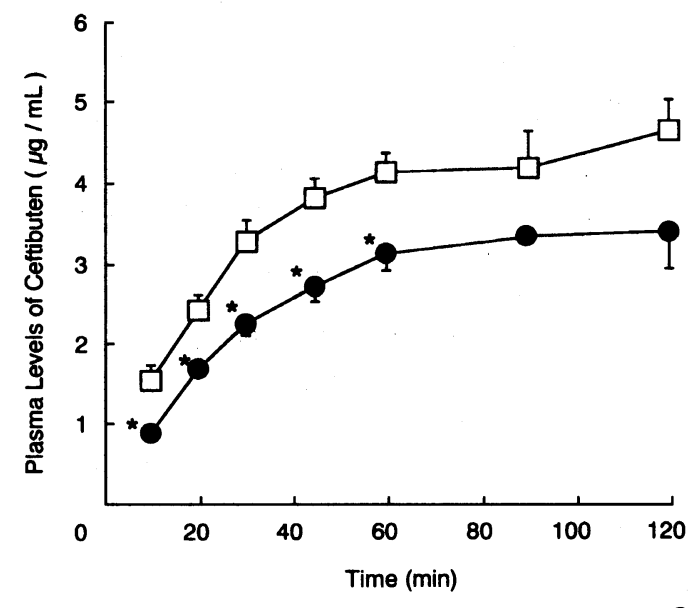

Fig. 7. Effect of Pretreatment with HepanED ${ }^{\circledR}$ on the Absorption of Ceftibuten from the Intestinal Loop

Ceftibuten $(2.5 \mathrm{mg} / 2 \mathrm{~mL})$ were administered into the intestinal loop after pretrearment with HepanED ${ }^{\circledR}$ preparation( $(\mathbf{O})$ or Modified Ringer solution ( $\square$ ) for 10 min. Each point represents the mean with S.E.M. $(\mathrm{n}=5){ }^{*} ; p<0.05$, Significantly different from control (without HepanED $\left.{ }^{\circledR}\right)$.

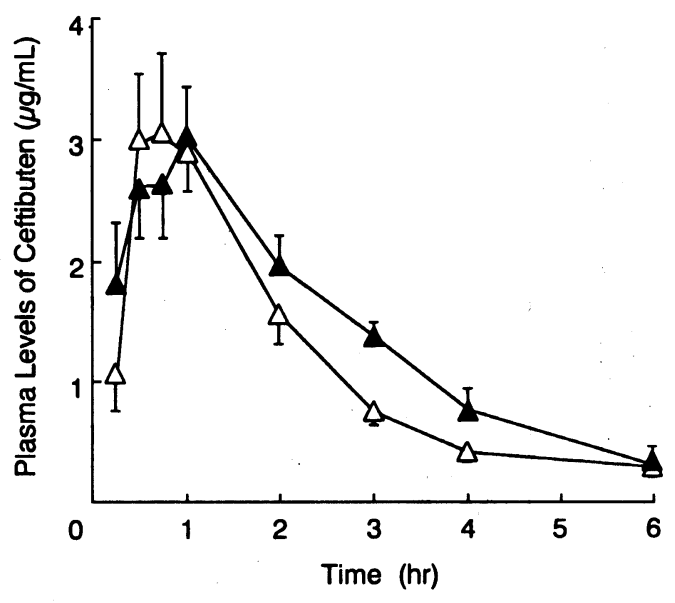

Fig. 8. Avoidance of Inhibitory Effect of HepanED ${ }^{\circledR}$ by the Time-Lag on the Administration of the Oral Nutrition Support

HepanED $^{\circledR}(\boldsymbol{\Delta})$ or saline $(\triangle)$ was administered $2 \mathrm{hr}$ before ceftibuten dosing. Each point represents the mean with S.E. M. of four determinations. ${ }^{*} ; p<0.05$, Si-gnificantly different from control (without HepanED ${ }^{\circledR}$ ). 
した時の回帰直線の傾き）をへパン ED 共存濃度 に対してプロットしたところ，良好な負の相関を 示した (Fig. 5 insert).

このような濃度依存性はエンテルードでも同様 に認められた（Fig. 6)。なお，希釈した経腸栄 養剤溶液の浸透圧, $\mathrm{pH}$ には変化は認められない ことを確認している. 小腸ループ内に直接投与し た場合でも有意な抑制効果が認められたことよ り,これらの体内動態の変化は胃排出の抑制に基 づくものではなく, 小腸壁通過段階での薬物相互 作用に起因する吸収抑制であることが示唆され る.

\section{4）ヘパン EDによる前处理}

小腸ループにヘパン ED を注入し，10分間放置 後ループ内を洗浄した後にこの部位を用いて薬物 吸収実験を行った. Fig. 7 に示したように，効果 は小さいものの CETB の吸収は有意に抑制され た。このことから経腸栄養剤中の薬物吸収に影響 を及ぼす成分は胃消化管内に比較的滞留しやすい ものであることが示唆される，そこで，経腸栄養 凬をラットに投与した後 2 時間経過してか.らセフ チブテンを経口投与し, その血中濃度推移を, 生 理食塩水を前投与したコントロールと比較した。 その結果，この吸収抑制は薬物と経腸栄養郕を 2 時間程度の時間差をおいて投与することで回避で きることが見いだされた（Fig. 8 ）。

\section{考察}

今回得られた結果は, 経腸栄養剤と他の薬剤を 投与するときには薬物の吸収の低下 - 遅延を考慮 し，投与時間をずらすなどの工夫が必要であるこ とを示唆しており, 適確な薬物治療を行う上で重 要な知見であると考えられる.

一方，レボフロキサシンに代表される両性イオ ン型薬物の場合は何ら影響を受けなかった。これ
らの結果は先に報告したセファレキシンの場合4) と良く一致している．現在までの検討結果では， アニオン型 (CETB，サリチル酸)，カチオン型 （シメチジン）を消化管内で呈する薬物が吸収抑 制を示したことから，これらの効果は影響を受け る薬物の解離型と関連した共通特性があることが 示唆される.

現在，経腸栄養療法の頻度は多くなく，これら の薬物相互作用についての報告は少ない。しかし ながら, 今後在宅療法の拡大と並行して IVH 等 の栄養療法は経腸療法に切り替わっていくことは 十分に考えられ，より多くの種類の薬物について 検討し経腸栄養剤との相互作用の詳細について薬 物の構造面から明らかにすることが必要となって くるであろう.

\section{引用文献}

1) B.A. Mueller, D.G. Brierton, S.B. Abel and L.Bowman, Antimicrobial. Agent Chemother., 38, 2101-2105 (1994)

2) M. L. Piccolo, Z.Toossi and N.Goldman, Am. J.Hosp . Pharm., 51, 2697-2699 (1994).

3) M.L. Ebbert-Sauer and K.E. Bertch, "Pharmacotherapy ; A pathophysiologic approach", Second Edition, edited by J.T. DiPiro, R.L. Talbert, P.E. Hayes, G.C. Yee, G.R. Matzke and L.M. Posey, Appleton \& Lange Northwalk Connecticut, 1993, pp.2167-2169.

4）井関健，佐藤佳子，菅原満，宮崎勝巳，薬学雑 誌 14, 233-240 (1994).

5) V.Ganapathy, M.Brandsch and F.H. Leibach, "Physiology of the Gastrointestinal Tract", Third Edtion, edited by L.R. Jhonson, Raven Press. New York, 1994, pp.1773-1794.

6) S.G. Schultz, R.E. Fuisz and P.F.Curran, J. Gen. Physiol., 49, 849-866 (1966).

7) J.A.Ziemniak, D.A.Chiarmonte and J.J. Schentag, Clin. Chem., 27, 272-275 (1981).

8) M. Abdel-Rahim, D. Ezra, C. Peck and J. Lazar, Clin. Chem., 31, 621-623 (1985). 